\title{
EXEMPLO E VEROSSIMILHANÇA: OS USOS DA HISTÓRIA NO PRIMEIRO DISCURSO DE J-J ROUSSEAU ${ }^{1}$
}

\author{
Ciro Lourenço Borges Júnior ${ }^{2}$
}

Resumo: Uma das principais críticas ao Discurso sobre as ciências e as artes foi acerca do uso dos dados históricos na fundamentação da sua tese. E mesmo recentemente asseverou-se sobre os "fracos argumentos históricos" de Rousseau nesta obra. Diante disso, pretendemos questionar tal perspectiva de modo a salientar um tratamento filosófico da história pretendido por Rousseau, sendo que, primeiramente, partindo de um esclarecimento acerca da concepção de "induções históricas" no contexto do Discurso, introduzimos o conceito de verossimilhança como produto da relação entre causa e efeito, verificada não a partir dos fatos isolados, mas das relações entre os homens. Desta forma, concentrando-se nas ações descritas pelos historiadores, Rousseau não visa a verdade dos fatos, mas os princípios morais que amparavam essas ações. Assim, concluímos com a concepção de uma "história exemplar", essencial para o desenvolvimento ulterior do pensamento moral rousseauniano.

Palavras-chave: Rousseau - Primeiro Discurso - História - exemplo - verossimilhança

\section{Je vois que c'est par l'bistoire et les faits qu'il faudroit terminer cette dispute. ${ }^{3}$}

Conforme afirma Rousseau nas Observações ao rei da Polônia, uma das únicas objeções que ele define como "considerável" e que foi apresentada à sua tese acerca da relação necessária entre a cultura das ciências e das artes e a corrupção dos costumes foi

\footnotetext{
${ }^{1}$ Texto apresentado no VIII Colóquio Nacional Filosofia da História: Tempo, História e Sociedade e retomado em minha dissertação de mestrado intitulada Verdade e virtude: os fundamentos da moral no pensamento de J-J Rousseau, defendida em 2015 no Departamento de Filosofia da Faculdade de Filosofia, Letras e Ciências Humanas da Universidade de São Paulo- USP.

2 Doutorando em Ética e Filosofia Política no Departamento de Filosofia - USP, sob orientação do professor Dr. Milton Meira do Nascimento. E-mail: cirolourenco@usp.br.

${ }^{3}$ Observações, OC (CEuvres Complètes), T III, p. 44 [p. 70]. A edição do Discurso sobre as ciências e as artes (abreviado $D C A)$ que utilizamos é a das Euvres Complètes lançada pela Gallimard em 5 vols. na coleção "Bibliothèque de la Pléiade”. A tradução em português utilizada é a realizada por Maria Ermantina Galvão, publicada pela Martins Fontes (2a ed., 1999). Temos, afinal, como referência padrão o exemplo a seguir: DCA, OC, T III, p. 14 [p. 26], sendo, na sequência, (i) título da obra, (ii) abreviatura "OC", (iii) tomo, (iv) página e, quando for o caso, (v) a página da edição da tradução utilizada entre colchetes. As respostas e refutações dos adversários de Rousseau referentes à polêmica são citadas segundo a edição de Michel Launay das Euvres Complètes de Rousseau (Seuil, 3 vols., 1971), abreviada por OC Launay, precedida do nome do autor e título da resposta.
} 
escrita por D’Alembert. Num trecho de sua Resposta, Stanislas questiona se acaso “não será ao temperamento, à falta de ocasião, à míngua de objeto, à economia do governo, aos costumes, às leis, a qualquer outra causa que não às ciências" que se deva considerar a origem dos vícios e, portanto, da corrupção dos costumes ${ }^{4}$. Em suma, trata-se da mesma questão que D'Alembert havia estabelecido no Discurso Preliminar ${ }^{5}$, todavia, o filósofo francês, afirmando como o rei que a corrupção dos costumes se deveria à "causas completamente diferentes", afirma por seu turno que essa é uma questão que talvez nem a própria moral possa resolver. É o que parece decorrer, afinal, da própria letra de D'Alembert: "as letras contribuem certamente a tornar a Sociedade mais amável; seria difícil provar que os homens se encontram melhores e a virtude mais comum; mas é um privilégio que se pode disputar à própria moral". 6

Mas em que se baseia essa manobra evasiva que pretende buscar a origem da corrupção em "causas completamente diferentes"? Tanto Rousseau, ao afirmar que tal questão "encerra grandes concepções e exigiria esclarecimentos extensos demais", como D'Alembert, que julga que a "enumeração [destas causas] seria tão longa como delicada", parecem referir-se justamente ao método adotado pelo genebrino para auferir as provas necessárias à confirmação de sua tese geral, ou seja, o método histórico. Olhando para a estrutura do Discurso sobre as ciências e as artes, o que aparece logo após a fórmula "onde não há nenhum efeito, não há causa que procurar" é justamente o início das enumerações de exemplos de povos retirados da história que, em suma, deveriam corroborar com o argumento rousseauniano. A problemática decorrente dos limites desse método não é ignorada por Rousseau, afinal, como ele afirma nas Observações ao rei Stanislas, "criticam-me de ter pretendido tomar os meus exemplos de virtude aos antigos. É bem provável que teria encontrado ainda mais se pudesse ter remontado a mais longe no tempo." ${ }^{10}$ Logo, deslocar o debate proposto por Rousseau do terreno da história para causas de outra natureza ou "da própria moral" pretende não somente salientar os limites de um tal método histórico como, em última instância, negar a validade que a história pode ter para questões que dizem respeito aos costumes e, portanto, de natureza moral.

\footnotetext{
${ }^{4}$ Stanislas, Resposta, OC Launay, T II, p. 73. Rousseau retoma em suas Observações esse trecho por completo. OC, T III, p. 43 [p. 68].

${ }^{5}$ E Rousseau faz questão de apontar isso a Stanislas: "aqui não posso deixar passar em silêncio uma objeção considerável que já me foi feita por um filósofo”. Observacõoes, OC, T III, p. $42-43$ [p. 68].

${ }^{6}$ D'Alembert, Discours préliminaire, p. 143.

7 Observacões, OC, T III, p. 43 [p. 68].

${ }^{8}$ D'Alembert, Discours préliminaire, p. 143.

${ }^{9}$ Discours sur les sciences et les arts [doravante DCA], OC, T III, p. 9 [p. 15].

${ }^{10}$ Observações, OC, T III, p. 42 [p. 67-68].
} 
Desse modo, considerando que é o próprio Rousseau quem considera tais objeções razoáveis, como ainda podemos tratar o problema da história no contexto do Discurso sobre as ciências e as artes sem que, como implicitamente parece inferir Stanislas ${ }^{11}$, esteja Rousseau lançando mão de dados tomados arbitrariamente?

Muito já se salientou que a questão proposta pela Academia de Dijon em 1750 fazia referência a um determinado contexto histórico. Questionando, portanto, se os costumes haviam se aperfeiçoado com o reestabelecimento das ciências e das artes, a Academia acabou propondo não apenas um exercício de análise sobre os costumes desde o início do chamado Renascimento (ou Renascença), mas também não podia deixar de trazer à tona a comparação entre os costumes modernos e aqueles dos povos antigos ${ }^{12}$. Na primeira objeção endereçada ao genebrino, o abade Raynal, reunindo as opiniões dos leitores do Mercure de France, afirmava a necessidade de Rousseau "definir o ponto de onde parte para designar a época da decadência e, remontando a esta primeira época, comparar os costumes daquele tempo com os nossos" 13

Em algumas passagens do Discurso poderíamos inferir que Rousseau, de fato, teria a intenção de estabelecer esses "pontos de partida" necessários para uma justa compreensão do processo de corrupção que se desenrolou sobre sociedades diversas. A primeira parte do Discurso, tal como Goldschmidt nos chamou a atenção, após os primeiros parágrafos que pretendiam dar uma resposta direta à questão acadêmica, destina a maioria de suas linhas à apresentar os "fatos" que de modo geral servem de provas para a tese de Rousseau. O que se tem são exemplos de povos que, por um lado, se lançaram no comércio das ciências e das artes e, de outro, aqueles povos que "preferiram outros exercícios àqueles do espírito"14 Tal como denominou Goldschmidt, na "tabela de presença" temos o Egito, a Grécia, a Roma imperial, Constantinopla, a China contemporânea; e na "tabela de ausência" encontram-se os Persas, os Citas, os Germânicos, a Roma republicana e a Suíça também contemporânea. ${ }^{15}$

Todavia, para além da identificação de povos e "testemunhos" que Rousseau utiliza para servir de prova ao argumento que as ciências corrompem costumes, é preciso notarmos, por um lado, a concepção de história difundida no século XVIII e, por outro, o valor que o

\footnotetext{
${ }^{11}$ Conforme Rousseau: "criticam-me ainda, numa máxima geral, de paralelos odiosos, nos quais entram, dizem, menos zelo e equidade do que inveja de meus compatriotas e irritação contra meus contemporâneos." Observações, OC, T III, p. 42 [p. 68].

12 Relembremos um importante debate que teve lugar nos fins do século XVII, adentrando o XVIII, e foi convencionado chamá-lo de a "querela dos antigos e dos modernos". Rousseau foi, de certo modo, um dos últimos a contribuir para a querela. Cf. a completíssima coletânea de textos intitulada La querelle des anciens et des modernes: XVIIe-XVIIIe siècles, com organização de Marc Fumaroli e Anne-Marie Lecoq.

${ }^{13}$ Raynal, Observações, OC Launay, T II, p. 69 [p. 280-281].

${ }^{14}$ DCA, OC, T III, p. 12 [p. 18].

${ }^{15}$ Goldschmidt, Anthropologie et Politique, p. 28.
} 
filósofo genebrino atribui aos ditos "fatos históricos". No Prospectus da Enciclopédia, Diderot reduzia a história aos fatos ou, segundo "a explicação detalhada do sistema dos conhecimentos humanos" "16, à memória; e, de acordo com o verbete história, escrito por Voltaire, em oposição à fábula, a história é ainda "o relato dos fatos tidos como verdadeiros" ${ }^{\prime 17}$.

$\mathrm{Na}$ economia do Discurso, fica claro que o recurso aos fatos e à história dos povos segue imediatamente após um dos parágrafos mais importantes e que afirma justamente sua "proposição geral", tal como a define na sua Carta ao abade Raynal. "Nossas almas, sentencia Rousseau, foram se corrompendo à medida que nossas ciências e nossas artes avançaram para a perfeição." ${ }^{18}$ Assim como bem notou Goldschmidt, Rousseau parte de uma questão de fato, ou seja, a corrupção inequívoca dos costumes da época, para uma questão geral que, conforme ele estabelece no Prefácio a Narciso, é relativa à "influência que a cultura das ciências deve ter em qualquer circunstância sobre os costumes dos povos" ${ }^{19}$ Ao propor, afinal, uma proposição geral que deve ser tratada e, em última instância, comprovada, Rousseau volta-se à história para recolher os "testemunhos" que a confirme (ou a contradiga).

A crítica à erudição como critério de verdade busca demonstrar que em tais questões, digamos, filosóficas, a memória deve se associar à razão ${ }^{20}$, logo, como podemos ler numa nota de suas Observações à refutação de Stanislas, enquanto seus adversários faziam as "listas de todos os bandos de salteadores que infestaram a terra e que, em geral, não eram homens muito sábios", Rousseau exortava-os a "não se esfalfarem nessa pesquisa, a não ser que a considerem necessária para mostrar erudição"21. Não se trata de listar os povos ignorantes e corrompidos, afinal, a relação que o genebrino afirma ter provado está entre a cultura das ciências e artes e a corrupção dos costumes. É justamente essa questão que está na base da resposta irônica que Rousseau dirige a Gautier:

o Sr. Gautier se dá ao trabalho de informar-me que há povos viciosos que não são eruditos, e eu bem que já imaginava que os calmucos, os beduínos, os cafres não eram prodígios de virtude nem de erudição. Se o Sr. Gautier

\footnotetext{
16 Diderot, Prospectus. "L'Histoire est des faits; et les faits sont ou de Dieu, ou de l'Homme, ou de la Nature. Les faits qui sont de Dieu appartiennent à l'Histoire sacrée, les faits qui sont de l'homme, appartiennent à l'Histoire civile, et les faits qui sont de la nature se rapportent à l'Histoire naturelle."

17 Voltaire, verbete "Histoire".

18 DCA, OC, T III, p. 9 [p. 15].

19 Prefácio a Narciso, OC, T II, p. 965.

20 "Eu poderia ainda deixar de lado as provas de raciocínio e, para colocar o Sr. Gautier em seu terreno, citarlhe fatos." Carta a Grimm, OC, T III, p. 69 [p. 55].

${ }^{21}$ Observações, OC, T III, p. 54, note * [p. 285-286, nota 24].
} 
houvesse tido os mesmos cuidados para mostrar-me algum povo erudito que não fosse vicioso, ter-me-ia surpreendido mais. ${ }^{22}$

Nesse sentido, portanto, seria preciso convirmos que ao lançar mão da história, Rousseau não pretende apenas recorrer à memória e aos fatos como um exercício de erudição, mas para atender os requisitos de seu pensamento neste Discurso e que se encontra resumido no Prefácio a Narciso: "comecei pelos fatos e mostrei que os costumes degeneraram em todos os povos do mundo à medida que o gosto do estudo e das letras se espalhou entre eles". Seguindo o rastro deixado pelos fatos históricos e que chegaram por meio dos testemunhos dos historiadores, Rousseau conclui por meio das suas "induções históricas" que "o gosto das letras sempre anuncia em um povo um começo de corrupção que ele acelera muito prontamente" 23 . Logo, é inútil "censurar-me [...] erros de história"24, diz Rousseau no Prefácio de uma segunda Carta a Bordes, enquanto não se apresentar as provas factuais que contradizem sua proposição.

Os fatos, por conseguinte, jamais terão para Rousseau um caráter objetivo e definitivo na busca pela verdade, de modo que a história será pensada apenas como "crônicas incertas" às quais é preciso suprir com "investigações filosóficas” 25 . Não há propriamente dizendo uma certeza histórica, uma verdade inerente ao fato. Enquanto testemunhos apresentados por outros homens, cujos interesses são praticamente impossíveis de perscrutar, o único produto desta relação entre observador e fato relatado, entre historiador e filósofo, é a verossimilhança. Os fatos, por exemplo, constantemente retomados no decorrer do Discurso, nos autoriza concluir que os primeiros gregos foram realmente virtuosos, contudo, essa verdade, enquanto nos chega por meio da linguagem soberba de seus historiadores, impõe, por sua vez, uma desconfiança que não se esvai senão à medida que se lança o olhar para mais perto ${ }^{26}$. O que é posto em dúvida, todavia, não são os fatos em si mesmos, mas a validade dos relatos, pois, como diz Rousseau, "as testemunhas são partes no processo" 27 .

${ }^{22}$ Carta a Grimm, OC, T III, p. 62 [p. 45].

23 Prefácio a Narciso, OC, T II, p. 965.

${ }^{24}$ Prefácio de uma carta a Bordes, OC, T III, p. 105 [p. 130].

${ }^{25}$ DCA, OC, T III, p. 17 [p. 25].

${ }^{26}$ Num trecho bastante curioso de sua Última Resposta, Rousseau apresenta claramente sua desconfiança a respeito da integridade absoluta dos fatos: "Eu disse que os primeiros gregos foram virtuosos antes que a ciência os houvesse corrompido e não quero retratar-me acerca desse ponto, conquanto, examinando-os mais de perto, não deixo de desconfiar da solidez das virtudes de um povo tão tagarela, nem da justiça dos elogios que tanto gostava de se prodigalizar e que não vejo confirmados por nenhum outro depoimento." Última Resposta, OC, T III, p. 80-81 [p 95].

${ }^{27}$ Carta a Grimm, OC, T III, p. 61 [p 44]. 
Todavia, é preciso salientar que decorre desta constatação que no primeiro Discurso os fatos "não se prendem à questão" - expressão cara ao contexto do Discurso sobre a desigualdade -, afinal, como verificamos na forte constatação da primeira parte, eles representam a própria questão: “onde não há nenhum efeito, não há causa que procurar; porém aqui o efeito é certo, a depravação real”. ${ }^{28}$

A crítica à história como erudição, portanto, opõe Rousseau não apenas à ideia de história concebida por seus contemporâneos como, por outro lado, abre um caminho para que pensemos acerca sua utilidade para a compreensão do pensamento rousseauniano, sobretudo, no Discurso sobre as ciências e as artes. De um lado, de nada serve essa história que se alimenta apenas de tiranos, guerras e conspiradores, afinal, só oferecem maus exemplos; e de outro, é justamente esses relatos centrados em indivíduos e particulares que, ainda que sejam reis ou rainhas, diz muito pouco ou quase nada sobre a verdadeira condição do povo em geral. O que Rousseau define como o método mais apropriado a estudar os costumes de um povo a partir da história encontra-se numa nota muito interessante e que é importante retomar por completo:

Quando se trata de objetos tão gerais como os costumes e as maneiras de um povo, deve-se tomar cuidado para não se restringir a visão sempre aos exemplos particulares. Seria um meio de nunca perceber as fontes das coisas. Para saber se tenho razão de atribuir a polidez à cultura das letras, não é preciso investigar se este ou aquele erudito são pessoas polidas; mas é preciso examinar as relações que podem existir entre a literatura e a polidez e depois ver quais são os povos entre os quais tais coisas estavam reunidas ou separadas. Digo o mesmo do luxo, da liberdade e de todas as outras coisas que influenciam os costumes de uma nação e sobre as quais ouço, todos os dias, tantos raciocínios deploráveis. Examinar tudo isso em detalhes e acerca de alguns indivíduos não é filosofar, é perda de tempo e de reflexões, pois pode-se conhecer a fundo Pierre ou Jacques e ter-se feito muito pouco progresso no conhecimento dos homens. ${ }^{29}$

Deste modo, a leitura que Goldschmidt nos apresenta da "universalidade da tese" reivindicada por Rousseau no Discurso sobre as ciências e as artes é fundamental. "É notável, diz o comentador, que uma questão de fato seja resolvida por uma lei geral e que uma questão que diríamos sociológica, proposta pela Academia, desemboque em investigações

\footnotetext{
${ }^{28}$ DCA, OC, T III, p. 9 [p. 15].

${ }^{29}$ Observações, OC, T III, p. 53, note* [p. 285, nota 23].
} 
concernentes à filosofia da história". ${ }^{30}$ Quando pensamos, enfim, no uso que Rousseau faz da história, fica claro o caráter filosófico que ele pretende aplicar, contudo, é preciso compreendermos melhor o estatuto dessa filosofia da história no contexto do primeiro Discurso.

Em Ilustração e História, Maria das Graças de Souza nos apresenta duas perspectivas que são essenciais para pensarmos qualquer filosofia da história: na primeira, ressalta-se o modelo cíclico utilizado pelos historiadores gregos e romanos em que não se considera "o futuro de maneira prospectiva", de modo que "tudo o que acontece tem o mesmo caráter no passado e no futuro" ${ }^{31}$. A segunda perspectiva, associada à visão cristã do mundo, na qual se passou a colocar Deus como uma referência lógica e também histórica: estando o próprio deus no início de todas as coisas, passa a se considerar que "o mundo teve um começo" e, portanto, a história só pode ser concebida sob um aspecto linear ${ }^{32}$. Tratando-se, portanto, de duas posições irreconciliáveis, é preciso apontarmos para qual modelo se adequaria o Discurso sobre as ciências $e$ as artes.

A leitura que Maria das Graças propõe parte da constatação de que a tese de Rousseau sobre a corrupção dos costumes diante do gosto pelas letras alinha-se ao modelo de sentido linear, afinal, como ele próprio afirma no primeiro Discurso, "nossas almas foram se corrompendo à medida que nossas ciências e nossas artes avançaram para a perfeição." ${ }^{33}$ Como ela muito bem observou, "há portanto um antes e um depois", ao qual ainda poderíamos adicionar o fato que Rousseau afirma a irreversibilidade dessa condição afinal "nunca se viu um povo, uma vez corrompido, voltar à virtude." ${ }^{34}$ É, aliás, justamente essa irreversibilidade que permite dizer que essa "concepção linear da história" está marcada pela "degeneração". Numa passagem fundamental deste comentário, Maria das Graças afirma: "nessa espécie de teologia laicizada da história, é como se ficássemos apenas com os momentos do paraíso e do pecado. Não há, parece, redenção à vista." 35

Analisando, todavia, a filosofia da história decorrente das teses do primeiro Discurso, gostaríamos de salientar um problema que decorre muito diretamente da possibilidade, ou não, desta redenção. No âmbito dos escritos concernentes à problemática levanta pelo Discurso sobre as ciências e as artes, uma passagem do Prefácio a Narciso nos remete ainda a esse fatalismo aparentemente próprio da obra: "quando não há mais costumes deve-se preocupar apenas com a polícia"36, pois "não se trata mais de fazer com que os homens ajam bem, mas

\footnotetext{
${ }^{30}$ Goldschmidt, Anthropologie et Politique, p. 45.

${ }^{31}$ Souza, Ilustração e História, p. 66-67.

32 Souza, Ilustração e História, p. 67-68.

33 DCA, OC, T III, p. 9 [p. 15]. Grifo nosso.

34 Observações, OC, T III, p. 56 [p. 83].

35 Souza, Ilustração e História, p. 72.

36 Prefácio a Narciso, OC, T II, p. 973.
} 
somente distraí-los de fazer o mal". ${ }^{37}$ Entretanto, ainda de acordo com este Prefácio e como já citamos anteriormente, a tese sustentada por Rousseau é que "o gosto das letras sempre anuncia em um povo um começo de corrupção que ele acelera muito prontamente" 38 , ou seja, a história linear segue da proposição geral que Rousseau sustenta no Discurso. Para dizermos de outro modo, a perspectiva linear da história pensada nesta obra atende os critérios da "universalidade da tese", pois as ciências e as artes servirão sempre e em qualquer lugar de divisor de águas que estabelece um antes e um depois.

Embora Rousseau apresente uma tese universal para explicar o processo de corrupção dos costumes, ele não pretende sobrepor-se às especificidades de cada povo, ou seja, ele não é universalista ${ }^{39}$. O artigo indefinido da passagem citada do Prefácio é muito significativo, pois "um povo", um determinado povo, onde quer que ele se encontre, estará realmente sempre sujeito à proposição geral estabelecida por Rousseau, mas ela não pretende dizer que uma vez que esse determinado povo inicie seu processo de corrupção, todos os povos da terra forçosamente se corromperão. É o que explica, por exemplo, a coexistência de povos corrompidos e aqueles que defendiam suas virtudes. "Os costumes de Esparta sempre foram propostos como exemplo a toda a Grécia", diz Rousseau na sua Última resposta. "A Grécia inteira estava corrompida, ele prossegue, e ainda havia virtude em Esparta; a Grécia inteira era escrava, somente Esparta ainda era livre" ${ }^{40}$ Se não há, de fato, qualquer possibilidade de redenção para a antiga Grécia ou a França contemporânea, é possível vislumbrar nos exemplos da igualmente antiga Esparta ou a Suíça natal de Rousseau uma esperança de manutenção das virtudes dos seus habitantes e, por fim, de sua liberdade.

Dessa maneira, não podemos deixar de notar que Rousseau não se afere totalmente ao modelo linear de história, pois restam algumas características da história cíclica dos antigos nas entrelinhas do Discurso sobre as ciências e as artes, em especial, nessa perspectiva de que "os eventos do passado poderão acontecer de novo de maneira similar" "41, conforme nos mostrou Maria das Graças. O papel que os exemplos representam no contexto desta obra é fundamental, afinal, a vida desses Sócrates e Catões tem muito a oferecer para o filósofo que vai analisar suas histórias e também para os atuais governantes porventura responsáveis pela conservação de seu povo. Desta maneira, somente os exemplos retirados da história, por mais monstruosos que pareçam, para lembrarmos uma importante passagem das Considerações sobre o governo da Polônia de Rousseau, podem ensejar a pergunta: "o que nos impede de ser

\footnotetext{
37 Prefácio a Narciso, OC, T II, p. 972.

38 Prefácio a Narciso, OC, T II, p. 965.

${ }^{39}$ Cf. Radica, L'bistoire de la raison, p. 16 et seq.

40 Última Resposta, OC, T III, p. 83 [p. 99].

${ }^{41}$ Souza, Ilustração e História, p. 49.
} 
homens como eles?" ${ }^{42}$. Desta forma, é importante afirmar com Bento Prado Jr. que "a própria ideia de exemplo é indissociável de algo como uma possível imitação, ela implica necessariamente um mínimo de normatividade, e a norma remete sempre ao que deve ser normatizado." ${ }^{43}$

Para Rousseau, portanto, o recurso constante aos exemplos históricos, tal como nos apresenta Baucher, distancia o filósofo genebrino das correntes que privilegiavam a "o espirito de sistema e a demonstração analítica", sendo que tal escolha segue fundamentalmente uma necessidade de se buscar não verdades abstratas, mas "a via verdadeiramente humana da verdade" ${ }^{44}$. O exemplo histórico, por conseguinte, representa não apenas um papel ilustrativo, mas uma ferramenta que visa fundar a própria demonstração das verdades a qual segue um modelo indutivo, isto é, do particular ao geral. ${ }^{45}$ É somente a partir desta perspectiva que podemos concluir, com Bento Prado Jr., sobre o caráter normativo inerente aos exemplos. Seu encadeamento segue uma regra previamente estabelecida, isto é, os costumes degeneraram à medida que as ciências e artes se aperfeiçoaram, de modo que, ao fim e ao cabo, se instaure o que Baucher denomina como um "sistema de ecos" ${ }^{46}$, o qual permite passarmos de um caso ao outro e, por fim, à regra geral.

Assim sendo, conforme observou Maria das Graças, o "verdadeiro conhecimento dos fatos é inseparável do de suas causas e de seus efeitos" e nessa busca pelas causas, Rousseau reconhece nos exemplos históricos os princípios da boa ação e da virtude. Por conseguinte, podemos afirmar que "a história preconizada por Rousseau é, antes de tudo, uma história exemplar", pois trata-se de "uma história da qual se possa extrair lições morais" ${ }^{47}$. Assim como em suas obras posteriores, já no Discurso sobre as ciências e as artes, todavia, podemos afirmar com Maria das Graças que "a história está tão ligada à moral, que não se pode conhecer uma sem estar em condições de conhecer a outra". ${ }^{48}$

\footnotetext{
42 "Quando lemos a história antiga, acreditamo-nos transportados para um outro universo e entre outros seres. O que têm em comum os franceses, os ingleses, os russos, com os romanos e os gregos? Nada quase além da aparência. As fortes almas destes últimos parecem aos outros exageros da história. Como é que eles, que se sentem tão pequenos, pensariam que houve tão grandes homens? Existiram, contudo e eram humanos como nós: o que nos impede de ser homens como eles?”. Considerações sobre o governo da Polônia, OC, T III, p. 956 [p. 26].

43 Bento Prado Jr., A retórica de Rousseau, p. 104.

${ }_{44}$ Baucher, 'La fabrique des exemples dans le Discours [...]', p. 456.

${ }^{45}$ Cf. Baucher, 'La fabrique des exemples dans le Discours [...]', p. 459.

${ }^{46}$ Baucher, 'La fabrique des exemples dans le Discours [...]', p. 463.

${ }^{47}$ Souza, Ilustração e História, p. 49.

${ }^{48}$ Souza, Ilustração e História, p. 49. Ver ainda Emílio, OC T IV, p. 348 [p. 124].
} 


\section{EXAMPLE AND VERISIMILITUDE: THE USES OF HISTORY ON J-J ROUSSEAU'S FIRST DISCOURSE}

Abstract: One of the main critiques on the Discourse on the sciences and the arts is focused on the use of historical data that supports his thesis. And even recently some scholars have argued on the Rousseau's "weak historical arguments" in his discourse. Therefore, we intend to put this perspective in question to highlight the philosophical treatment of history intended by Rousseau. Proceeding, primarily, from a clarification of the concept of "historical inductions" in the context of the Discourse, we introduced the concept of verisimilitude as a product of a cause and effect consideration, not observed from the isolated facts, but emerging men in relation. Thus, focusing on the actions described by historians, Rousseau does not seek truth from facts, but from the moral principles that motivates these actions. Thus, we conclude with the concept of an "exemplary history" that is essential for the further development of Rousseau's moral thought.

Keywords: Rousseau - First Discourse - History - example - verisimilitude

\section{REFERÊNCIAS BIBLIOGRÁFICAS}

BAUCHER, Bérengère. La fabrique des exemples dans le Discours sur les sciences et les arts: de la morale à la politique. Dix-buitième siècle, Paris, nº 39, p. 455-469, 2007.

D'ALEMBERT, Jean le Rond. Discours préliminaire de l'Encyclopédie. Introd. e notas Michel Malherbe. Paris: J. Vrin, 2000.

DIDEROT, Denis ; D'ALEMBERT, Jean le Rond. Encyclopédie, on dictionnaire raisonné des sciences, des arts et des métiers, etc. University of Chicago: ARTFL Encyclopédie Project (Spring 2013 Edition), Robert Morrissey (ed). Disponível em: http://encyclopedie.uchicago.edu. Acesso em: 18 de dezembro de 2014.

GOLDSCHMIDT, Victor. Anthropologie et Politique: les principes du système de J-J Rousseau. 2ème ed. Paris: J. Vrin, 1984.

PRADO JR., Bento. A retórica de Rousseau e outros ensaios. Trad. Cristina Prado; Org. e apresentação Franklin de Mattos. São Paulo: Cosac Naify, 2008.

RADICA, Gabrielle. L'Histoire de la raison - Anthropologie, morale et politique chez Rousseau. Paris: Honoré Champion, 2008.

ROUSSEAU, Jean-Jacques. CEuvres Complètes. Éd. Bernard Gagnebin et Marcel Raymond. 5 Tomes. Paris: Éditions Gallimard, 1957-1995. "Bibliothèque de la Pléiade”.

Euvres Complètes. Préf. Jean Fabre. Introd., présent. et notes Michel Launay. 3 Tomes. Paris: Éditions du Seuil, 1971. "L'Intégrale". 
.Discurso sobre as ciências e as artes. Cronologia e introd. Jacques Roger. Trad. Maria Ermantina Galvão. 2 ed. São Paulo: Martins Fontes, 1999.

Emílio on Da educação. Trad. Roberto Leal Ferreira. 2. ed. São Paulo: Martins Fontes, 1999.

. Considerações sobre o Governo da Polônia. Trad. Luiz Roberto Salinas Fortes. São Paulo: Editora Brasiliense, 1982.

SOUZA, Maria das Graças de. Ilustração e história: o pensamento sobre a história no Iluminismo francês. São Paulo: Discurso Editorial, 2001. 